\title{
Measures of exposure to secondhand smoke: recent developments
}

\author{
Alistair Woodward
}

\section{Correspondence to}

Professor Alistair Woodward, School of Population Health, University of Auckland, Auckland 1142, New Zealand; a.woodward@auckland.ac.nz

Published Online First 9 October 2012

\section{SLinked}

- http://dx.doi.org/10.1136/ tobaccocontrol-2011-050296

- http://dx.doi.org/10.1136/ tobaccocontrol-2011-050298

- http://dx.doi.org/10.1136/ tobaccocontrol-2011-050301

\section{ABSTRACT}

About a third of the world's population is exposed to secondhand smoke (SHS), despite reductions in smoking prevalence in many countries. Accurate, cost-effective measures of exposure are needed in investigations of the health risks associated with SHS, and in studies of interventions to extend smoke-free environments. There have been important developments in the use of questionnaires, air quality monitoring and biomarkers, but still, there is no single, gold standard assessment of exposure to SHS. Choice of measure depends on circumstances, including cost, scale and time window.

It is more than 25 years since the US Surgeon General's report on the health consequences of involuntary smoking, ${ }^{1}$ but many people around the world are still exposed to secondhand smoke (SHS). According to one estimate, in 2004 approximately $40 \%$ of children, and $34 \%$ of adult non-smokers, were exposed to SHS worldwide, and there were about 603000 SHS-attributable deaths from heart disease, chest infections and cancer. ${ }^{2}$ In the Southeast Asian region in 2009, the proportion of youth (13-15 years) exposed to SHS in public places ranged from $37 \%$ (India) to $78 \%$ (Indonesia). ${ }^{3}$

Three papers in this issue of the journal set out to summarise the current state of knowledge in the field of SHS exposure assessment. ${ }^{4-6}$ Some things have not changed. There is, for instance, still no 'gold standard' in the measurement of SHS. All approaches have advantages and disadvantages, and the right measure will depend on circumstances. Questionnaires remain the only way of gathering information on extended periods of exposure, and are likely to be the most cost-effective measure in studies of very large populations, although they are prone to partial and possibly biased reporting. Biomarkers such as cotinine in saliva or urine provide accurate measures of recent exposure to SHS, but are relatively expensive, and may not be helpful in studies of diseases with long lag times. Environmental monitoring (eg, counting airborne particulates) can be conducted cheaply (after the initial investment in machinery), and this approach provides continuous measurements, with high sensitivity for nearby smoking, but personal exposures must be inferred, and results may be affected by other sources of particulates than tobacco smoke.

But the field is not static: there have been important developments. For instance, we have much more evidence linking biomarker-defined exposures to SHS and subsequent disease, ${ }^{7}$ and better measures of exposure are contributing to improved understanding of disease mechanisms. ${ }^{8}$ Another significant development is the work now underway to develop a common metric for exposure to fine particles, whatever the source, which aims to standardise risk assessments for SHS, active smoking and air pollution. ${ }^{9}$

The interpretation of measures of exposure has been affected by changes in the behaviour of smokers. In many countries the prevalence of smoking has fallen considerably in recent decades, as has the average amount smoked, and people have also changed the places in which they smoke (less likely to smoke indoors at home, for instance). This means that the concentrations of biomarkers such as cotinine and nicotine that distinguish active and passive smoking have to be revised downwards. In the US, on the basis of 1999-2004 National Health and Nutrition Examination Survey data it has been recommended that the optimal cut point for serum cotinine should be reduced from $14 \mathrm{ng} / \mathrm{ml}$ to $3 \mathrm{ng} / \mathrm{ml}^{10}$

Hitherto most research on SHS exposures has been carried out in developed countries, but there is a growing number of studies from low-income countries, including Latin America, Asia ${ }^{11}$ and Africa. ${ }^{12}$ There is evidently some variation in exposures indoors (for instance, higher intensities are observed in Asia and the Middle East than in Europe) but overall, the relation between living with a smoker and personal exposure to SHS appears to be broadly similar, wherever one lives. ${ }^{2}$ We have also seen the full range of measures of exposure applied in studies of comprehensive smoke-free interventions. ${ }^{13}$ The findings are generally very encouraging. In New Zealand, an investigation using repeated saliva cotinine measures found that legislation had reduced exposure to smoke in hotel bars by $90 \% .{ }^{14}$ Other countries have reported striking reductions in the population at large. ${ }^{15}$

There are still challenges, but we should take heart from the considerable progress that has been made in both the science and control of exposures to SHS.

Contributors AW was responsible for all aspects of preparing this paper.

Competing interests None.

Provenance and peer review Commissioned; internally peer reviewed.

\section{REFERENCES}

1. Surgeon General. The health consequences of involuntary smoking. Rockville, MD: US Department of Health and Human Services, 1986.

2. Oberg M, Jaakkola MS, Woodward A, et al. Worldwide burden of disease from exposure to second-hand smoke: a retrospective analysis of data from 192 countries. Lancet 2011;377:139-46.

3. Singh RJ, Lal PG. Second-hand smoke: a neglected public health challenge. India J Public Health 2011;55:192-8. 
4. Apelberg B, Hepp L, Avila-Tang E, et al. Environmental monitoring of secondhand tobacco smoke exposure. Tobacco Control 2013;22:147-55.

5. Avila-Tang E, Al-Delaimy W, Ashley D, et al. Assessing secondhand smoke exposure using biological markers. Tobacco Control 2013;22:164-71.

6. Avila-Tang E, Elf J, Cummings $\mathrm{M}$, et al. Assessing secondhand smoke exposure using reported measures. Tobacco Control 2012.

7. Hamer M, Stamatakis E, Kivimaki M, et al. Objectively measured secondhand smoke exposure and risk of cardiovascular disease. JAC 2010;56:18-23.

8. Chiu Y-HM, Spiegelman D, Dockery DW, et al. Secondhand smoke exposure and inflammatory markers in nonsmokers in the trucking industry. Environ. Health Perspect 2011;119:1294-300.

9. Pope CA, Burnett RT, Krewski D, et al. Cardiovascular mortality and exposure to airborne fine particulate matter and cigarette smoke: shape of the exposure-response relationship. Circulation 2009;120:941-8.

10. Benowitz NL, Bernert JT, Caraballo RS, et al. Optimal serum cotinine levels for distinguishing cigarette smokers and nonsmokers within different racial/ethnic groups in the United States between 1999 and 2004. Am J Epidemiol 2008;169:236-48.
11. Wipfli H, Avila-Tang E, Navas-Acien A, et al. Secondhand smoke exposure among women and children: evidence from 31 countries. Am J Public Health 2008;98:672-9.

12. Agbenyikey W, Wellington $\mathrm{E}$, Gyapong J, et al. Secondhand tobacco smoke exposure in selected public places (PM2.5 and air nicotine) and non-smoking employees (hair nicotine) in Ghana. Tobacco Control 2011;20: 107-11.

13. IARC. Evaluating the effectiveness of smoke-free policies. IARC Handbooks of Cancer Prevention 2009;13:1-348.

14. Fernando D, Fowles J, Woodward A, et al. Legislation reduces exposure to second-hand tobacco smoke in New Zealand bars by about $90 \%$. Tobacco Control 2007; 16:235-8.

15. Sims M, Mindell JS, Jarvis MJ, et al. Did smokefree legislation in England reduce exposure to secondhand smoke among nonsmoking adults? Cotinine analysis from the Health Survey for England. Environ Health Perspect 2011;120 $425-30$. 